\title{
RESEARCH
}

Open Access

\section{Changes in malaria patterns in Brazil over 28 years (1990-2017): results from the Global Burden of Disease Study 2017}

\author{
Juliana Maria Trindade Bezerra', David Soeiro Barbosa' ${ }^{1}$, Francisco Rogerlândio Martins-Melo ${ }^{2,3}$, \\ Guilherme Loureiro Werneck ${ }^{4}$, Érika Martins Braga ${ }^{5}$, Pedro Luiz Tauil ${ }^{6}$ and Mariângela Carneiro ${ }^{1,7^{*}}$ (D)
}

\begin{abstract}
Background: This study presents the malaria burden in Brazil from 1990 to 2017 using data from the Global Burden of Diseases, Injuries, and Risk Factors Study 2017 (GBD 2017), by analyzing disease burden indicators in federated units of the Legal Amazon and Extra-Amazon regions, as well as describing malaria cases according to Plasmodium species occurring in the country.

Methods: We used estimates from the GBD 2017 to report years of life lost due to premature death (YLLs), years lived with disability (YLDs), and disability-adjusted life years (DALYs) for malaria in Brazil, grouped by gender, age group, and Brazilian federated unit, from 1990 to 2017. Results are presented as absolute numbers and agestandardized rates (per 100,000 inhabitants) with 95\% uncertainty intervals (UI).

Results: At the national level, the age-standardized DALYs rate due to malaria decreased by $92.0 \%$, from 42.5 DALYs per 100,000 inhabitants (95\% UI 16.6-56.9) in 1990 to 3.4 DALYs per 100,000 inhabitants (95\% UI 2.7-4.7) in 2017. The YLLs were the main component of the total DALYs rate for malaria in 1990 (67.3\%), and the YLDs were the main component of the metric in 2017 (61.8\%). In 2017, the highest sex-age DALYs rate was found among females in the "<1-year-old" age group, with a 6.4 DALYs per 100,000 inhabitants (95\% UI 1.8-14.7) and among males in the age group of "20 to 24 years old", with a 4.7 DALYs per 100,000 inhabitants (95\% UI 3.3-9.9). Within the Brazilian Amazon region, the three federated units with the highest age-standardized DALYs rates in 2017 were Acre [28.4 (95\% UI 14.2-39.1)], Roraima [28.3 (95\% UI 13.5-40.2)], and Rondônia [24.7 (95\% UI 11.4-34.8)]. Concerning the parasite species that caused malaria, $73.5 \%$ of the total of cases registered in the period had Plasmodium vivax as the etiological agent.

(Continued on next page)
\end{abstract}

\footnotetext{
*Correspondence: mcarneiro@ufmg.br; mariangelaufmg@gmail.com

'Laboratory of Epidemiology of Infectious and Parasitic Diseases, Department

of Parasitology, Institute of Biological Sciences, Universidade Federal de

Minas Gerais, Belo Horizonte, Avenida Presidente Antônio Carlos, 6627,

Pampulha, Belo Horizonte, Minas Gerais 31270-901, Brazil

${ }^{7}$ Post-Graduation Program in Health Sciences, Infectology and Tropical

Medicine, Universidade Federal de Minas Gerais, Avenida Professor Alfredo Balena, 190, Santa Efigênia, Belo Horizonte, Minas Gerais 30130-100, Brazil

Full list of author information is available at the end of the article
}

C C The Author(s). 2020 Open Access This article is licensed under a Creative Commons Attribution 4.0 International License, which permits use, sharing, adaptation, distribution and reproduction in any medium or format, as long as you give appropriate credit to the original author(s) and the source, provide a link to the Creative Commons licence, and indicate if changes were made. The images or other third party material in this article are included in the article's Creative Commons licence, unless indicated otherwise in a credit line to the material. If material is not included in the article's Creative Commons licence and your intended use is not permitted by statutory regulation or exceeds the permitted use, you will need to obtain permission directly from the copyright holder. To view a copy of this licence, visit http://creativecommons.org/licenses/by/4.0/ The Creative Commons Public Domain Dedication waiver (http://creativecommons.org/publicdomain/zero/1.0/) applies to the data made available in this article, unless otherwise stated in a credit line to the data. 


\begin{abstract}
(Continued from previous page)
Conclusions: The results of the GBD 2017 show that despite the considerable reduction in the DALYs rates between 1990 and 2017, malaria remains a relevant and preventable disease, which in recent years has generated more years of life lost due to disability than deaths. The states endemic for malaria in the Amazon region require constant evaluation of preventive and control measures. The present study will contribute to the direction of current health policies aimed at reducing the burden of malaria in Brazil, as knowing the geographical and temporal distribution of the risk of death and disability of this disease can facilitate the planning, implementation, and improvement of control strategies aimed at eliminating the disease.
\end{abstract}

Keywords: Malaria, Burden of disease, Disability-adjusted life year, Brazil

\section{Background}

Malaria is an infectious disease with episodic acute manifestations and is caused by protozoan parasites of the genus Plasmodium [1, 2]. Five species of Plasmodium can infect humans; however, $P$. vivax and $P$. falciparum are the main responsible for causing the disease, with the latter showing a high mortality rate and being predominant in African countries [1-4]. Despite being considered treatable and presenting a favorable evolution when effective health actions are adopted, malaria remains a relevant disease from a global health perspective [5-7].

In 2017, the World Health Organization (WHO) estimated that about 219 million [95\% confidence interval (CI) 203-262 million] new cases of malaria had occurred worldwide, corresponding to an increase of two million notifications in relation to the previous year (2016: 217 million, 95\% CI 200-259 million) [8].

Regarding the malaria in the Americas, a total of 568, 283 confirmed cases were reported in 2016, an increase of 116,000 in relation to the previous year. Between 2010 and 2016, 19 of the 21 endemic countries in the region reported autochthonous transmission of malaria. Brazil, Colombia, Guyana, Haiti, Peru, and Venezuela are responsible for the greatest disease burden, representing $94 \%$ of all the cases in the Americas $[9,10]$.

In Brazil, in the early 1940s, two thirds of the 40 million inhabitants lived in areas endemic for malaria, and between 6 and 8 million infections and around 80,000 malaria-related deaths occurred each year [11-15]. In this context, the National Malaria Service was established, and anti-malaria campaigns were initiated throughout the country $[11,12]$.

Later, the number of malaria cases increased considerably in the Amazon region as a result of large development projects, such as the construction of roads that facilitated the implementation of ores and timber extraction, livestock, and agricultural settlements, as well as the expansion of colonization and migration of workers to the region [15-17]. Nowadays, malaria still represents a major public health problem in Brazil, with the highest number of cases being registered in the Brazilian
Amazon region. In this area, 174,522 cases of malaria have been reported from January to November 2017, which represents an increase of $48 \%$ in relation to the same period in 2016, when 117,832 cases of the disease were reported. These have been caused mainly by $P$. vivax, followed by $P$. falciparum, and, to a smaller extent, P. malariae [18].

The Global Burden of Disease (GBD) is a descriptive epidemiological study that, since the 1990s, has been quantifying and comparing the magnitude of health losses due to diseases and injuries and identifying risk factors associated with location, sex, age, and year [19, 20]. The GBD study uses the disability-adjusted life year (DALYs), a measure of the health loss due to fatal and nonfatal disease burden, as the population's primary health metric. The DALYs are estimated by the sum of years lived with disabilities (YLDs) and years of life lost (YLLs) due to premature death for a given cause [19-25].

To the best of our knowledge, this is the first national analysis of the malaria burden stratified by sex, age group, and federated units in Brazil, one of the American countries most affected by the disease. Although the burden of malaria in Brazil has been quantified at the national level, there are clear disparities among different regions, and subnational analyses are needed. Considering that most reports of malaria in Brazil result from $P$. vivax infection, over the years, it is observed that, although the disease does not have a high mortality rate, it affects a significant number of cases with great social and economic impact. The analysis of the burden of malaria goes beyond the knowledge about the incidence and mortality of the disease and can be considered an additional tool for understanding this health problem. Therefore, the results of the GDB will allow a better understanding of the country's malaria burden, a key step in policy implementation as it leads to the compression of morbidity caused by the disease. Identifying levels and trends of malaria burden can assist health authorities in planning interventions, monitoring processes, and assessing the impact and effectiveness of adopted disease control measures. In the present study, we analyzed the malaria burden in Brazil and its 27 federated units using 
the data from the GBD 2017 study describing the main disease burden metrics DALYs, YLDs, and YLLs, in federated units in the Legal Amazon and Extra-Amazon regions, as well as describing malaria cases according to Plasmodium species occurring in the country.

\section{Methods}

\section{Study area}

The Federative Republic of Brazil is the largest country in South America and the fifth largest worldwide in territorial area, with 8.5 million $\mathrm{Km}^{2}$ (equivalent to $47 \%$ of the South American territory) [26]. Regarding population size, the country is the second largest in the Americas and the sixth in the world, with approximately 210 million inhabitants in 2018 [26].

In this study, we present results for malaria burden at the national level and for all the 27 federated units. The data are presented considering the five geographic regions (North, Northeast, Central-West, Southeast, and South) [27], as well as the Legal Amazon (Acre-AC, Amapá-AP, Amazonas-AM, Pará-PA, RondôniaRO, Roraima-RR, Tocantins-TO, Maranhão-MA, and Mato Grosso-MT) and the non-endemic ExtraAmazon (Alagoas-AL, Bahia-BA, Ceará-CE, Paraíba-PB, Pernambuco-PE, Piauí-PI, Rio Grande do Norte-RN, Sergipe-SE, Distrito Federal-DF, GoiásGO, Mato Grosso do Sul-MS, Espírito Santo-ES, Minas Gerais-MG, Rio de Janeiro-RJ, São Paulo-SP, Paraná-PR, Rio Grande do Sul-RS, and Santa Catarina-SC) $[27,28]$.

We compared the malaria estimates from the GBD 2017 study for 2017 with those generated in 1990. These estimates are available on the GBD study platform at http://vizhub.healthdata.org/gbd-compare and http:// ghdx.healthdata.org/gbd-results-tool.

\section{GBD overview}

The GBD study is coordinated by the Institute for Health Metrics and Evaluation at the University of Washington, USA [24] and consist of a systematic and scientific effort to quantify the comparative magnitude of health losses due to diseases, injuries, and risk factors by sex, age, and location over time [25]. The general methodological approaches used to estimate the metrics in the GBD 2017 are detailed in previous publications [19-23]. The GBD study uses the disability-adjusted life years (DALYs) of a given population as the main health metric. The DALYs results from the sum of the years of disability (YLDs) and the years of life lost due to premature death (YLLs) [22]. A DALY represents 1 year of healthy life lost due to a specific illness or injury [22].

Herein, we used the data and estimates from the GBD 2017 to explore the malaria burden in Brazil from 1990 to 2017. The GBD 2017 provides a comprehensive annual assessment of mortality and morbidity estimates for more than 300 diseases and injuries and 84 risk factors for 195 countries and territories from 1990 to 2017 [21, 22, 24, 25]. The GBD 2017 list of hierarchy of disease causes is organized into four levels, which are mutually exclusive and collectively exhaustive [24, 25]. The cause of malaria was defined and identified according to the International Classification of Diseases, 9th (ICD-9) and 10th (ICD-10) Revisions: ICD-9 (Code 084), ICD-9 BTL (Code B052), and ICD-10 (Codes B50-B54, P37.3, P37.4) [29].

The GBD data sources for Brazil have been described elsewhere [30-34]. The mortality data and the data used to generate the YLLs estimates came from the Brazilian Mortality Information System (Sistema de Informações sobre Mortalidade-SIM) and were adjusted by other national and international sources. The main sources of morbidity data, used for the estimation of the YLDs, were the Information System of Diseases Notification (Sistema de Informação de Agravos de NotificaçãoSINAN), the Epidemiological Surveillance Information System-Case Report (Sistema de Informação de Vigilância Epidemiológica - Notificação de casos-SIVEP/ Malária), the Hospital Information System of the Unified Health System (Sistema de Informações Hospitalares do Sistema Único de Saúde-SIH/SUS), and the Outpatient Information System of the Unified Health System (Sistema de Informações Ambulatoriais do Sistema Único de Saúde-SIA/SUS) [30-32]. Additional data on the prevalence of diseases from published Brazilian populationbased studies and databases from control programs were also used in the GBD study [30-32].

In the GBD study, each death is attributed to a single underlying cause, which is the cause that initiated the series of events that led to death, in accordance with the ICD principles [20]. In the GBD 2017, mortality subregistration and the redistribution of "garbage codes" were corrected based on the GBD 2017 redistribution algorithms [20]. "Garbage codes" are the assignment of causes of death that could not or should not be classified as the underlying cause of death [20]. The GBD 2017 used the Cause of Death Ensemble model (CODEm), negative binomial regression, and natural history models to estimate the number of causes of deaths for neglected tropical diseases (NTDs) by location, sex, age, and year. The modeling strategy that they used for morbidity estimation and validation has been published elsewhere [22]. All available data that the GBD study uses is required to meet a minimum standard of acceptable quality for each disease. The GBD 2017 used the Bayesian regression analytic tool DisMod-MR 2.1 to synthesize consistent estimates of prevalence and incidence of nonfatal outcomes by sex, age, year, and location using a wide range of updated and standardized analytical procedures [22]. 
The burden of malaria was assessed by the metrics of incidence, number of deaths, years of life lost due to premature death (YLLs), years lived with disability (YLDs), and disability-adjusted life year (DALYs $=$ YLLs + YLDs). The YLLs express the effect of premature deaths on the population and results from the multiplication of the number of deaths due to malaria at a certain age by the standard life expectancy. The GBD 2017 considered a global standard life expectancy of 72.9 (95\% UI $72.6-$ 73.2) years at birth, based on the lowest observed death rates for each 5-year age range in 2017 [35]. The YLDs express the sum of the prevalence of sequelae related to malaria multiplied by the disability weight [22]. The disability weight reflects the severity of health loss associated with a given disease and is presented on a scale varying from 0 (perfect health) to 1 (equivalent to death) [22]. The sum of the YLLs and the YLDs yields the DALYs [22].

Herein, we present the estimates as age-standardized rates by 100,000 inhabitants. The age-standardized rates were calculated using the GBD's world population standard. The metrics are presented with their respective 95\% uncertainty intervals (95\% UI) and the relative percentages of change. We also present the annual rates of change (ARC) estimated by the GBD 2017, to highlight the variations between 1990 and 2017 [36].

We ranked the federated units from the highest to the lowest value of DALYs for malaria. Additionally, we used the software QGIS version 2.18.2 (Las Palmas, Spain) to create thematic maps, which were used to show the spatial distribution of the metrics DALYs, YLLs, and YLDs, and the percentages of change over time.

\section{Brazilian malaria data reports and species of infecting parasites}

Since the GBD 2017 does not estimate the malaria burden for each species of Plasmodium, we assessed the number of confirmed cases of the disease considering the species of the etiological agent over the years. In our analyses, we considered the infections caused by $P$. vivax, P. falciparum, and "others" (which include coinfection with $P$. vivax and P. falciparum, infections by $P$. malariae, infections by $P$. ovale, and infections by non $P$. falciparum species, according to the Brazilian Ministry of Health classification data).

The graph of cases by species over time was plotted using three main sources of information: The number of disease cases confirmed in the country between 1990 and 2002 were obtained from (i) the SUS Epidemiological Report (Informe Epidemiológico do SUS) [37], available at http://scielo.iec.gov.br/scielo.php?script=sci arttext\&pid=S0104-16731997000100004 and (ii) the National Health Foundation (Fundação Nacional de Saúde-FUNASA) [38], available at http://www.funasa. gov.br/epi/malaria/malaria0.htm, while the notifications from 2003 to 2017 were collected from (iii) the Epidemiological Surveillance Information System-Case Report (Sistema de Informação de Vigilância Epidemiológica Notificação de casos-SIVEP/Malária) [39], available at http://200.214.130.44/sivep_malaria/.

\section{Ethical considerations}

The protocol for this study was approved by the Research Ethics Committee of the Federal University of Minas Gerais, Belo Horizonte, Brazil (Project CAAE 62803316.7.0000.5149).

\section{Results}

\section{GBD estimates at the national level}

The main metrics on malaria burden and relative change from 1990 to 2017 in Brazil are presented in Table 1. In 2017, the incidence rate was 97.2 cases per 100,000 inhabitants (95\% UI 80.4-117.2), and the mortality rate was 0.02 deaths per 100,000 inhabitants (95\% UI 0.010.06), representing a reduction of $96.4 \%$ and $95.0 \%$, respectively, in comparison with 1990. The DALYs rate also decreased in the country, going from 42.5 DALYs per 100,000 inhabitants (95\% UI 16.6-56.9) in 1990 to 3.4 DALYs per 100,000 inhabitants (95\% UI $2.7-4.7)$ in 2017, representing a percentage change of $-92.0 \%$ and an ARC of $-9.3 \%$ (Table 1 ).

In 1990, the YLLs rate [28.6 (95\% UI 4.9-36.9) per 100,000 inhabitants] accounted for $67.3 \%$ of the DALYs, while the YLDs rate [13.9 (95\% UI 7.2-24.6) per 100,000 inhabitants] corresponded to $32.7 \%$ of the total DALYs due to malaria. Over the years, the contributions of the YLLs and the YLDs to the total DALYs of malaria changed. In 2017, 38.2\% of the DALYs rate corresponded to the YLLs [1.3 (95\% UI 1.0-2.9) per 100,000 inhabitants], and $61.8 \%$ corresponded to the YLDs [2.1 (95\% UI 1.52.6) per 100,000 inhabitants] (Fig. 1).

\section{GBD estimates by sex and age groups}

Over the years, the DALYs, YLLs, and YLDs rates were similar between genders. In the early 1990s, males presented higher values of DALYs and YLLs (Fig. 2a and b) in contrast with females, who presented higher values of YLDs in the same period (Fig. 2c). A marked decrease was observed in the three metrics between 1990 and 2017. The DALYs rates for males and females were less than 10 per 100,000 inhabitants from the year 2000 onwards (Fig. 2a). Regarding the YLLs and YLDs, rates lower than 10 per 100,000 inhabitants were verified in 1996 and 1992, respectively (Fig. 2b and c).

The year 1990 also showed the highest rates per 100, 000 inhabitants for the DALYs, YLLs, and YLDs, for both males and females, in all age groups. In that year, the highest DALYs rate was found in the age group of 
Table 1 Incidence rates, number of deaths, years of life lost due to premature death (YLLs), years lived with disability (YLDs), and disability-adjusted life years (DALYs) for malaria in Brazil in 1990 and 2017

\begin{tabular}{|c|c|c|c|c|c|c|c|}
\hline \multirow[t]{2}{*}{ Metrics } & \multicolumn{2}{|c|}{ Absolute number $N(95 \%$ UI) } & \multirow[b]{2}{*}{$\begin{array}{l}\text { Relative } \\
\text { change (\%) }\end{array}$} & \multicolumn{2}{|c|}{ Rate per 100,000 inhabitants ( $95 \%$ UI) } & \multirow[b]{2}{*}{$\begin{array}{l}\text { Relative } \\
\text { change (\%) }\end{array}$} & \multirow[b]{2}{*}{ ARC 1990-2017 (\% } \\
\hline & 1990 & 2017 & & 1990 & 2017 & & \\
\hline Incidence & $\begin{array}{l}4612,232 \\
(2,315,926-8,359,156)\end{array}$ & $\begin{array}{l}209,669 \\
(173,992-251,852)\end{array}$ & -95.4 & $\begin{array}{l}2700.1 \\
(1387.8-4827.4)\end{array}$ & $\begin{array}{l}97.2 \\
(80.4-117.2)\end{array}$ & -96.4 & -12.3 \\
\hline Deaths & $\begin{array}{l}670 \\
(123-852)\end{array}$ & $\begin{array}{l}58 \\
(42-145)\end{array}$ & -91.3 & $\begin{array}{l}0.4 \\
(0.08-0.5)\end{array}$ & $\begin{array}{l}0.02 \\
(0.01-0.06)\end{array}$ & -95.0 & -10.2 \\
\hline YLLs & $\begin{array}{l}47,423 \\
(8249-61,500)\end{array}$ & $\begin{array}{l}2802 \\
(2101-6282)\end{array}$ & -94.0 & $\begin{array}{l}28.6 \\
(4.9-36.9)\end{array}$ & $\begin{array}{l}1.3 \\
(1.0-2.9)\end{array}$ & -95.4 & -11.3 \\
\hline YLDs & $\begin{array}{l}22,968 \\
(11,768-41,202)\end{array}$ & $\begin{array}{l}4323 \\
(3265-5552)\end{array}$ & -81.1 & $\begin{array}{l}13.9 \\
(7.2-24.6)\end{array}$ & $\begin{array}{l}2.1 \\
(1.5-2.6)\end{array}$ & -85.6 & -7.0 \\
\hline DALYS & $\begin{array}{l}70,391 \\
(27,531-94,759)\end{array}$ & $\begin{array}{l}7125 \\
(5672-10,218)\end{array}$ & -89.8 & $\begin{array}{l}42.5 \\
(16.6-56.9)\end{array}$ & $\begin{array}{l}3.4 \\
(2.7-4.7)\end{array}$ & -92.0 & -9.3 \\
\hline
\end{tabular}

Absolute numbers and age-standardized rates per 100,000 inhabitants are presented, along with relative change and annual rate of change (ARC), $1990-2017$. $N$ absolute value of the metric, $95 \%$ UI uncertainty interval of $95 \%, \%$ percentage, YLLs years of life lost due to premature death, YLDs years lived with disability, $D A L Y$ s disability-adjusted life years, $A R C$ annual rate of change

"< 1 year old" for both sexes, being 235.3 (95\% UI 24.9360.9) for males (Fig. 3a) and 302.3 (95 \% UI 20.7512.3) for females (Fig. 3b). This age group ("< $<$ year old") also showed the highest YLLs rates: 219.6 (95\% UI 11.7-345.1) for males (Fig. 3c) and 285.0 (95\% UI 6.2494.7) for females (Fig. 3d). The indicator YLLs presented the highest rates among males in the age group of "1 to 4 years old" [34.0 (95\% UI 12.2-76.3)] (Fig. 3e) and among females in the age group of " 5 to 9 years old" [31.2 (95\% UI 10.8-74.3)] (Fig. 3f).

In 2017, the highest DALYs rates were observed among males in the age group of "20 to 24 years old" [4.7 (95\% UI 3.3-9.9)] (Fig. 3a) and among females "<1 year old" [6.4 (95\% UI 1.8-14.7)] (Fig. 3b). The highest YLLs rates for both sexes were found in the age group of "< 1 year old", being 3.4 (95\% UI 1.5-10.5) for males
(Fig. 3c) and 5.6 (95\% UI 1.1-13.6) for females (Fig. 3d). Regarding the YLDs, the age group with the highest rate among males was that of " 5 to 9 years old" [(2.8 (95\% UI 1.6-4.9)] (Fig. 3e) and that of "15 to 19 years old" [3.6 (95\% UI 2.2-6.2)] among females (Fig. 3f).

\section{GBD estimates by federated units}

From 1990 to 2017, the incidence and DALYs rates per 100,000 inhabitants for malaria reduced in all federated units. The highest incidence and DALYs rates per 100, 000 inhabitants were found in most of the states in the Legal Amazon region both in 1990 and 2017. In terms of the incidence rates, the state of Acre (in the North of Brazil and within the Legal Amazon region) presented the highest rates per 100,000 inhabitants both in 1990 [94,748.3 (95\% UI 49,564.6-172,108.5)] and in 2017

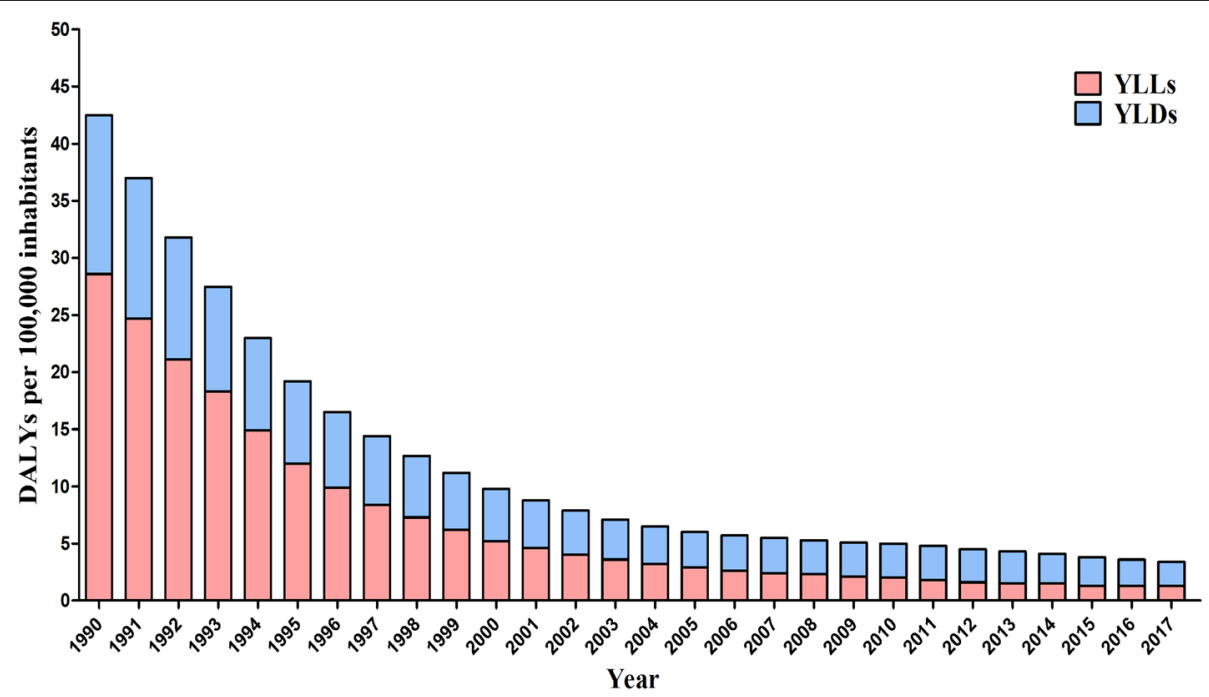

Fig. 1 Disability-adjusted life years (DALYs) for malaria. Age-standardized rates per 100,000 inhabitants are presented, along with the contribution of the rates of years of life lost due to premature death (YLLs) and years lived with disability (YLDs). Brazil, 1990-2017 


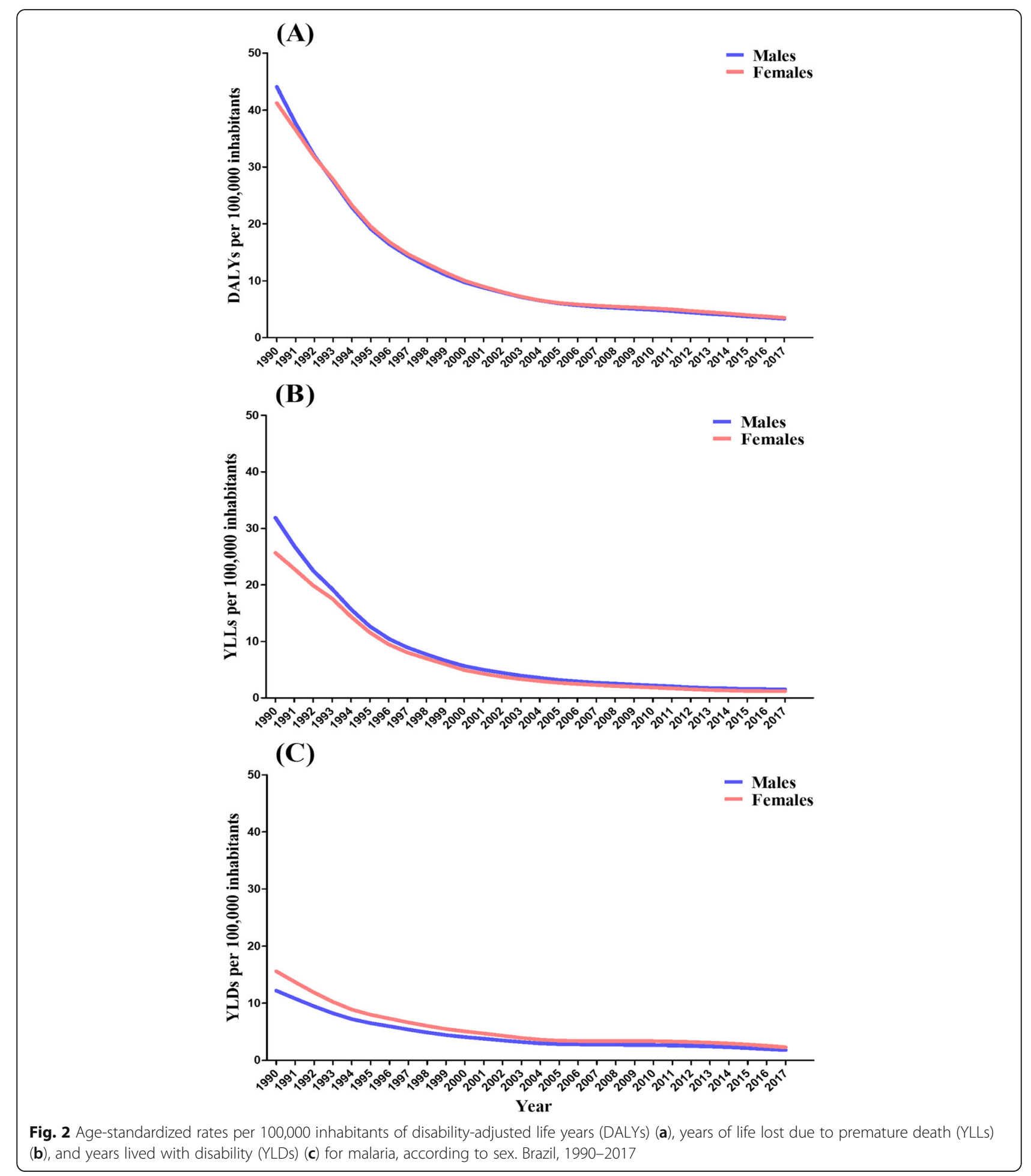

[3296.0 (95\% UI 2677.7-4074.3)]. The highest DALYs rates were detected in the state of Rondonia (also located in the North region and within the Legal Amazon area) in 1990 [1243.1 (95\% UI 583.5-1788.2)] and in the state of Acre in 2017 [28.5 (95\% UI 14.339.1)] (Table 2).
Among the states located in the Extra-Amazon region, Piauí (in the Northeast of Brazil) stood out as presenting the highest incidence rates per 100,000 inhabitants in 1990 [163.2 (95\% UI 75.2-322.1)] and in 2017 [1.8 (95\% UI 1.5-2.1)], showing a percentage of change of $-98.8 \%$. The highest DALYs rates were verified in the state of 
Bezerra et al. Population Health Metrics 2020, 18(Suppl 1):5

Page 7 of 15

(A)

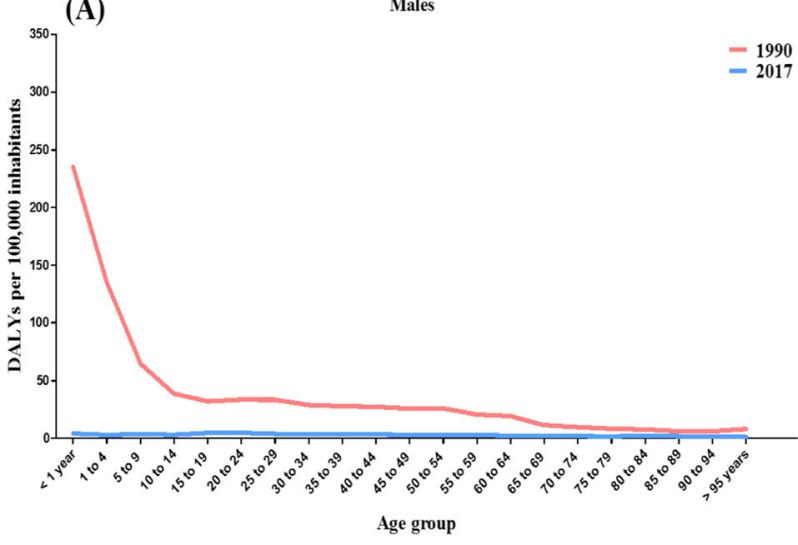

(C)

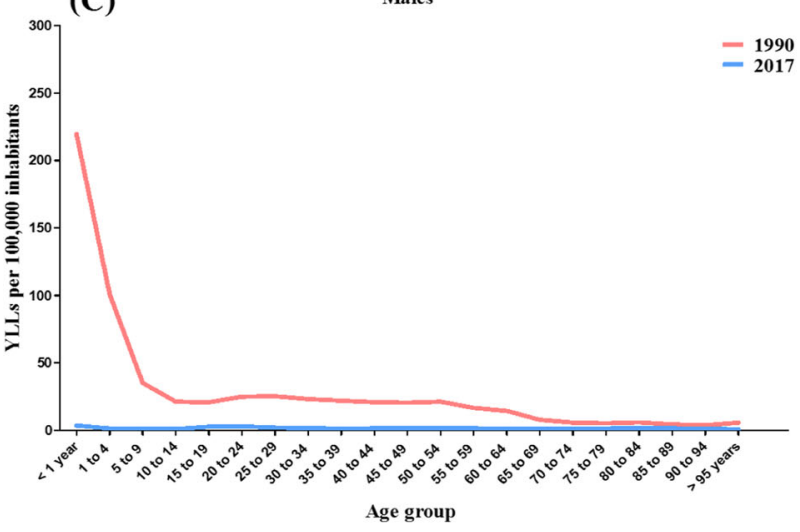

(E)

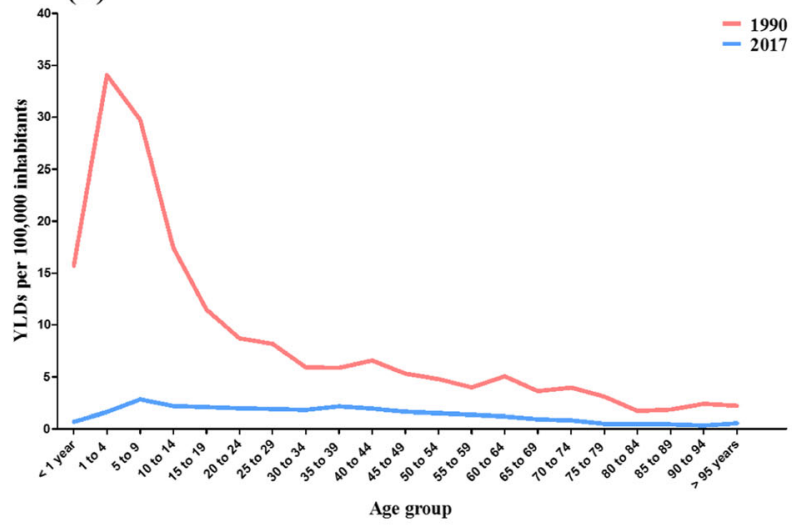

(B)

${ }^{350} 7$

(1)

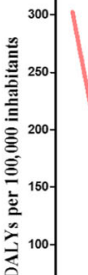

Females

-1990
-2017

Fig. 3 Age-standardized rates per 100,000 inhabitants of disability-adjusted life years (DALYs), years of life lost due to premature death (YLLs), and years lived with disability (YLDs), according to sex and age group. Brazil, 1990-2017. DALYs per 100,000 inhabitants for males (a) and females (b) at each age group. ILs per 100,000 inhabitants for males (c) and females (d) at each age group. YLDs per 100,000 inhabitants for males (e) and females (f) at each age group

Goiás (Central-West Brazil) in 1990 [29.1 (95\% UI 5.439.3)] and in 2017 [2.7 (95\% UI 2.0-4.5)], showing a percentare change of $-90.7 \%$ (Table 2 ).

In 1990, the three most expressive DALYs rates were found in the states of Rondônia [1243.2 (95\% UI 583.51788.2)], Roraima [1080.9 (95\% UI 285.1-1591.3)], and Acre [1048.1 (95\% UI 328.5-1546.2)], all of which are located in the North of Brazil and within the Legal Amazorn. In these three states, the YLLs represented the greatest contribution to the DALYs in that year, contribting with $65.0 \%$ in Rondônia, $66.4 \%$ in Roraima, and 62.4\% in Acre (Figs. Aa and 5). In 2017, the same three states showed the highest DALYs rates, albeit ranking at different positions: Acre ranked first [28.5 (95\% UI 14.3- 
Table 2 Incidence and DALYs rates for malaria, according to federated units and regions

\begin{tabular}{|c|c|c|c|c|c|c|}
\hline \multirow[b]{2}{*}{ Regions } & \multicolumn{2}{|c|}{$\begin{array}{l}\text { Incidence per } 100,000 \\
\text { inhabitants }(95 \% \text { UI) }\end{array}$} & \multirow[b]{2}{*}{ Relative change (\%) } & \multicolumn{2}{|c|}{$\begin{array}{l}\text { DALYs per } 100,000 \\
\text { inhabitants }(95 \% \mathrm{UI})\end{array}$} & \multirow[b]{2}{*}{ Relative change (\%) } \\
\hline & 1990 & 2017 & & 1990 & 2017 & \\
\hline \multicolumn{7}{|l|}{ Legal Amazon* } \\
\hline \multicolumn{7}{|l|}{ North** } \\
\hline Acre & $\begin{array}{l}94,748.3 \\
(49,564.6-172,108.5)\end{array}$ & $\begin{array}{l}3296.0 \\
(2677.7-4074.3)\end{array}$ & -96.5 & $\begin{array}{l}1048.1 \\
(328.5-1546.2)\end{array}$ & $\begin{array}{l}28.5 \\
(14.3-39.1)\end{array}$ & -97.2 \\
\hline Amapá & $\begin{array}{l}31,556.8 \\
(14,412.0-64,852.0)\end{array}$ & $\begin{array}{l}2335.5 \\
(1894.6-2805.1)\end{array}$ & -92.5 & $\begin{array}{l}469.7 \\
(70.5-655.5)\end{array}$ & $\begin{array}{l}24.5 \\
(11.8-34.0)\end{array}$ & -94.7 \\
\hline Amazonas & $\begin{array}{l}46,631.1 \\
(24,532.6-83,569.1)\end{array}$ & $\begin{array}{l}2029.4 \\
(1609.0-2495.3)\end{array}$ & -95.6 & $\begin{array}{l}257.4 \\
(113.2-443.0)\end{array}$ & $\begin{array}{l}14.2 \\
(10.1-20.3)\end{array}$ & -94.4 \\
\hline Pará & $\begin{array}{l}18,978.0 \\
(10,098.0-33,150.1)\end{array}$ & $\begin{array}{l}373.1 \\
(305.2-456.6)\end{array}$ & -98.0 & $\begin{array}{l}401.0 \\
(60.4-568.7)\end{array}$ & $\begin{array}{l}13.1 \\
(6.6-17.4)\end{array}$ & -96.7 \\
\hline Rondônia & $\begin{array}{l}90,883.6 \\
(44,462.1-178,645.5)\end{array}$ & $\begin{array}{l}1332.5 \\
(1060.3-1610.7)\end{array}$ & -98.5 & $\begin{array}{l}1243.2 \\
(583.5-1788.2)\end{array}$ & $\begin{array}{l}24.7 \\
(11.4-34.9)\end{array}$ & -98.0 \\
\hline Roraima & $\begin{array}{l}90,107.4 \\
(45,008.0-163,702.4)\end{array}$ & $\begin{array}{l}2717.6 \\
(2185.9-3350.8)\end{array}$ & -96.9 & $\begin{array}{l}1080.9 \\
(285.1-1591.3)\end{array}$ & $\begin{array}{l}28.3 \\
(13.6-40.3)\end{array}$ & -97.3 \\
\hline Tocantins & $\begin{array}{l}171.1 \\
(83.3-318.2)\end{array}$ & $\begin{array}{l}3.7 \\
(3.0-4.6)\end{array}$ & -97.8 & $\begin{array}{l}46.1 \\
(6.1-80.8)\end{array}$ & $\begin{array}{l}5.6 \\
(2.9-7.3)\end{array}$ & -87.8 \\
\hline \multicolumn{7}{|l|}{ Northeast** } \\
\hline Maranhão & $\begin{array}{l}2306.8 \\
(1120.2-4306.2)\end{array}$ & $\begin{array}{l}34.5 \\
(28.6-41.6)\end{array}$ & -98.5 & $\begin{array}{l}27.1 \\
(13.8-47.3)\end{array}$ & $\begin{array}{l}4.4 \\
(3.3-5.7)\end{array}$ & -83.7 \\
\hline \multicolumn{7}{|l|}{ Central-West** } \\
\hline Mato Grosso & $\begin{array}{l}2351.8 \\
(1139.6-4243.4)\end{array}$ & $\begin{array}{l}48.5 \\
(39.0-61.4)\end{array}$ & -98.1 & $\begin{array}{l}250.7 \\
(13.2-360.8)\end{array}$ & $\begin{array}{l}8.2 \\
(3.4-11.2)\end{array}$ & -96.7 \\
\hline \multicolumn{7}{|l|}{ Extra-Amazon* } \\
\hline \multicolumn{7}{|l|}{ Northeast** } \\
\hline Alagoas & $\begin{array}{l}66.9 \\
(23.0-161.1)\end{array}$ & $\begin{array}{l}0.1 \\
(0.09-0.2)\end{array}$ & -99.8 & $\begin{array}{l}4.3 \\
(2.8-9.0)\end{array}$ & $\begin{array}{l}1.9 \\
(1.2-4.6)\end{array}$ & -55.8 \\
\hline Bahia & $\begin{array}{l}33.9 \\
(13.3-74.8)\end{array}$ & $\begin{array}{l}0.1 \\
(0.09-0.2)\end{array}$ & -99.7 & $\begin{array}{l}4.2 \\
(3.1-7.2)\end{array}$ & $\begin{array}{l}1.9 \\
(1.2-4.4)\end{array}$ & -54.7 \\
\hline Ceará & $\begin{array}{l}10.0 \\
(4.8-18.6)\end{array}$ & $\begin{array}{l}0.3 \\
(0.2-0.4)\end{array}$ & -97.0 & $\begin{array}{l}4.2 \\
(2.9-7.1)\end{array}$ & $\begin{array}{l}1.9 \\
(1.3-4.0)\end{array}$ & -54.7 \\
\hline Paraíba & $\begin{array}{l}6.2 \\
(2.9-11.4)\end{array}$ & $\begin{array}{l}0.2 \\
(0.1-0.3)\end{array}$ & -96.7 & $\begin{array}{l}3.8 \\
(2.5-6.9)\end{array}$ & $\begin{array}{l}1.9 \\
(1.2-4.1)\end{array}$ & -50.0 \\
\hline Pernambuco & $\begin{array}{l}31.9 \\
(13.3-67.5)\end{array}$ & $\begin{array}{l}0.1 \\
(0.09-0.2)\end{array}$ & -99.6 & $\begin{array}{l}4.3 \\
(2.9-8.6)\end{array}$ & $\begin{array}{l}1.9 \\
(1.2-4.4)\end{array}$ & -55.8 \\
\hline Piauí & $\begin{array}{l}163.2 \\
(75.2-322.1)\end{array}$ & $\begin{array}{l}1.8 \\
(1.5-2.1)\end{array}$ & -98.8 & $\begin{array}{l}7.0 \\
(5.1-9.5)\end{array}$ & $\begin{array}{l}2.2 \\
(1.6-3.9)\end{array}$ & -68.5 \\
\hline Rio Grande do Norte & $\begin{array}{l}16.8 \\
(8.3-29.7)\end{array}$ & $\begin{array}{l}0.4 \\
(0.3-0.5)\end{array}$ & -97.6 & $\begin{array}{l}4.6 \\
(3.4-6.8)\end{array}$ & $\begin{array}{l}2.0 \\
(1.3-4.4)\end{array}$ & -56.5 \\
\hline Sergipe & $\begin{array}{l}36.7 \\
(15.7-75.6)\end{array}$ & $\begin{array}{l}0.2 \\
(0.1-0.3)\end{array}$ & -99.4 & $\begin{array}{l}4.4 \\
(3.1-7.9)\end{array}$ & $\begin{array}{l}2.0 \\
(1.3-4.5)\end{array}$ & -54.5 \\
\hline \multicolumn{7}{|l|}{ Central-West** } \\
\hline Distrito Federal & $\begin{array}{l}20.4 \\
(8.6-42.4)\end{array}$ & $\begin{array}{l}1.0 \\
(0.8-1.2)\end{array}$ & -95.0 & $\begin{array}{l}9.8 \\
(5.2-12.4)\end{array}$ & $\begin{array}{l}2.1 \\
(1.4-3.7)\end{array}$ & -78.5 \\
\hline Goiás & $\begin{array}{l}32.0 \\
(14.2-65.5)\end{array}$ & $\begin{array}{l}1.3 \\
(1.0-1.6)\end{array}$ & -95.9 & $\begin{array}{l}29.1 \\
(5.4-39.3)\end{array}$ & $\begin{array}{l}2.7 \\
(2.0-4.5)\end{array}$ & -90.7 \\
\hline Mato Grosso do Sul & $\begin{array}{l}18.6 \\
(8.4-36.6)\end{array}$ & $\begin{array}{l}0.8 \\
(0.6-0.9)\end{array}$ & -95.6 & $\begin{array}{l}11.2 \\
(5.0-14.8)\end{array}$ & $\begin{array}{l}2.2 \\
(1.6-4.2)\end{array}$ & -80.3 \\
\hline \multicolumn{7}{|l|}{ Southeast** } \\
\hline Espírito Santo & $\begin{array}{l}39.7 \\
(17.7-81.9)\end{array}$ & $\begin{array}{l}1.6 \\
(1.3-1.9)\end{array}$ & -95.9 & $\begin{array}{l}6.1 \\
(4.6-8.6)\end{array}$ & $\begin{array}{l}2.2 \\
(1.5-4.5)\end{array}$ & -63.9 \\
\hline
\end{tabular}


Table 2 Incidence and DALYs rates for malaria, according to federated units and regions (Continued)

\begin{tabular}{|c|c|c|c|c|c|c|}
\hline \multirow[b]{2}{*}{ Regions } & \multicolumn{2}{|c|}{$\begin{array}{l}\text { Incidence per } 100,000 \\
\text { inhabitants ( } 95 \% \text { UI) }\end{array}$} & \multirow[b]{2}{*}{ Relative change (\%) } & \multicolumn{2}{|c|}{$\begin{array}{l}\text { DALYs per } 100,000 \\
\text { inhabitants }(95 \% \text { UI) }\end{array}$} & \multirow[b]{2}{*}{ Relative change (\%) } \\
\hline & 1990 & 2017 & & 1990 & 2017 & \\
\hline Minas Gerais & $\begin{array}{l}21.8 \\
(10.2-40.9)\end{array}$ & $\begin{array}{l}0.4 \\
(0.3-0.5)\end{array}$ & -98.1 & $\begin{array}{l}4.3 \\
(3.1-7.0)\end{array}$ & $\begin{array}{l}1.9 \\
(1.2-4.1)\end{array}$ & -55.8 \\
\hline Rio de Janeiro & $\begin{array}{l}9.6 \\
(4.7-17.6)\end{array}$ & $\begin{array}{l}0.5 \\
(0.4-0.6)\end{array}$ & -94.7 & $\begin{array}{l}4.3 \\
(3.0-8.4)\end{array}$ & $\begin{array}{l}1.9 \\
(1.2-4.4)\end{array}$ & -55.8 \\
\hline São Paulo & $\begin{array}{l}12.4 \\
(6.1-22.4)\end{array}$ & $\begin{array}{l}0.5 \\
(0.4-0.6)\end{array}$ & -95.9 & $\begin{array}{l}4.4 \\
(3.2-7.2)\end{array}$ & $\begin{array}{l}1.8 \\
(1.2-3.7)\end{array}$ & -59.0 \\
\hline \multicolumn{7}{|l|}{ South** } \\
\hline Paraná & $\begin{array}{l}14.3 \\
(6.5-29.7)\end{array}$ & $\begin{array}{l}0.6 \\
(0.5-0.8)\end{array}$ & -95.8 & $\begin{array}{l}7.1 \\
(4.8-9.0)\end{array}$ & $\begin{array}{l}2.0 \\
(1.4-4.2)\end{array}$ & -71.8 \\
\hline Rio Grande do Sul & $\begin{array}{l}4.0 \\
(1.7-80.7)\end{array}$ & $\begin{array}{l}0.1 \\
(0.09-0.2)\end{array}$ & -97.5 & $\begin{array}{l}4.0 \\
(2.9-6.5)\end{array}$ & $\begin{array}{l}1.9 \\
(1.2-4.1)\end{array}$ & -52.5 \\
\hline Santa Catarina & $\begin{array}{l}8.7 \\
(3.8-17.9)\end{array}$ & $\begin{array}{l}0.3 \\
(0.2-0.4)\end{array}$ & -96.5 & $\begin{array}{l}5.4 \\
(4.1-7.4)\end{array}$ & $\begin{array}{l}2.0 \\
(1.3-3.9)\end{array}$ & -62.9 \\
\hline
\end{tabular}

Age-standardized rates per 100,000 inhabitants are shown, along with the relative changes. Brazil, 1990-2017

$95 \%$ UI uncertainty interval of $95 \%, \%$ percentage

* Malaria transmission areas in Brazil, considering the Legal Amazon region, comprising nine states in the Brazilian geographic regions North, Northeast, and Central-West (Acre, Amapá, Amazonas, Pará, Rondônia, Roraima, Tocantins, Maranhão, and Mato Grosso), and the Extra-Amazon region, comprising the other 17 states and the Federal District located in the geographic regions Northeast, Central-West, Southeast, and South (Alagoas, Bahia, Ceará, Paraíba, Pernambuco, Piauí, Rio Grande do Norte, Sergipe, Distrito Federal, Goiás, Mato Grosso do Sul, Espírito Santo, Minas Gerais, Rio de Janeiro, São Paulo, Paraná, Rio Grande do Sul, and Santa Catarina)

**The five Brazilian geographic regions: North, Northeast, Central-West, Southeast, and South

39.1)], followed by Roraima [28.3 (95\% UI 13.6-40.3)] and Rondônia [24.7 (95\% UI 11.4-34.9)]. In the first two, the greatest contribution to the DALYs came from the YLDs, with an observed contribution of $54.2 \%$ in the state of Acre and $50.1 \%$ in the state of Roraima. In the state of Rondônia, on the other hand, the YLLs contributed with $53.0 \%$ of the DALYs (Figs. $4 \mathrm{~b}$ and 5 ). In all the federated units, a decrease in the DALYs rates was observed from 1990 to 2017 (Figs. 4a and b and 5).

Among the states located in the Extra-Amazon region, Goiás (in the geographic region, Central-West) presented the highest DALYs rates per 100,000 inhabitants both in 1990 [29.1 (95\% UI 5.4-39.3)] and in 2017 [2.7 (95\% UI 2.0-4.5)]. The YLLs contributed with $87.2 \%$ of the DALYs in 1990, and the YLDs contributed with $61.5 \%$ of the DALYs in 2017 (Figs. 4a and $\mathrm{b}$ and 5).

Among the federated units within the Legal Amazon region, the three with the highest percentage of change over the years were Rondonia, Roraima, and Acre. This observation was consistent for the three metrics: DALYs [(Rondônia (-98.0\%), Roraima (-97.4\%), and Acre (97.3\%)], YLLs [Rondônia (-98.4\%), Roraima (-98.0\%), and Acre $(-98.0 \%)$ ], and YLDs [Rondônia (-97.3\%), Roraima (-96.1\%), and Acre (-96.1\%)] (Fig. 6).

In the Extra-Amazon region, the state of Piauí (Northeast Brazil) presented the highest percentage of change for YLDs (-65.7\%), while Goiás (Central-West Brazil) showed the highest percentages of change for YLLs (95.5\%) and DALYs (-90.9\%) (Fig. 6).

\section{Brazilian estimates: number of cases of malaria by etiological agent}

Between 1990 and 2017, 11,327,462 cases of malaria were confirmed in Brazil. With regards to the parasite species that caused the disease, $73.5 \%$ of the total number of cases had $P$. vivax as the etiological agent, while $25.5 \%$ were caused by $P$. falciparum, and $1.0 \%$ was caused by other species. The years of 1999 and 2005 had the highest number of cases in the historical series (Fig. 7).

\section{Discussion}

To the best of our knowledge, this is the first comprehensive effort to analyze the burden of malaria in Brazil using data from the GBD 2017, comprising a period of 28 years (from 1990 to 2017) and examining both genders at different age groups and in all the Brazilian federated units (both in the Legal Amazon and the ExtraAmazon regions). The present study showed a reduction in all disease burden indicators in the country during the study period, with a $92.0 \%$ decrease in the DALYs per 100,000 inhabitants, a $95.0 \%$ decrease in mortality, and a $96.4 \%$ decrease in disease incidence. Reductions were evidenced for both sexes, at all age groups, and in all the federated units of the country. An important feature associated with this change was the decrease in the contribution of YLLs to the DALYs rate. In 1990, the YLLs contributed with $67.2 \%$ of the DALYs rate, a percentage that decreased to $38.2 \%$ in 2017 , thus reaffirming the substantial reduction in the mortality due to malaria, which was reflected in the decrease of the YLLs. 


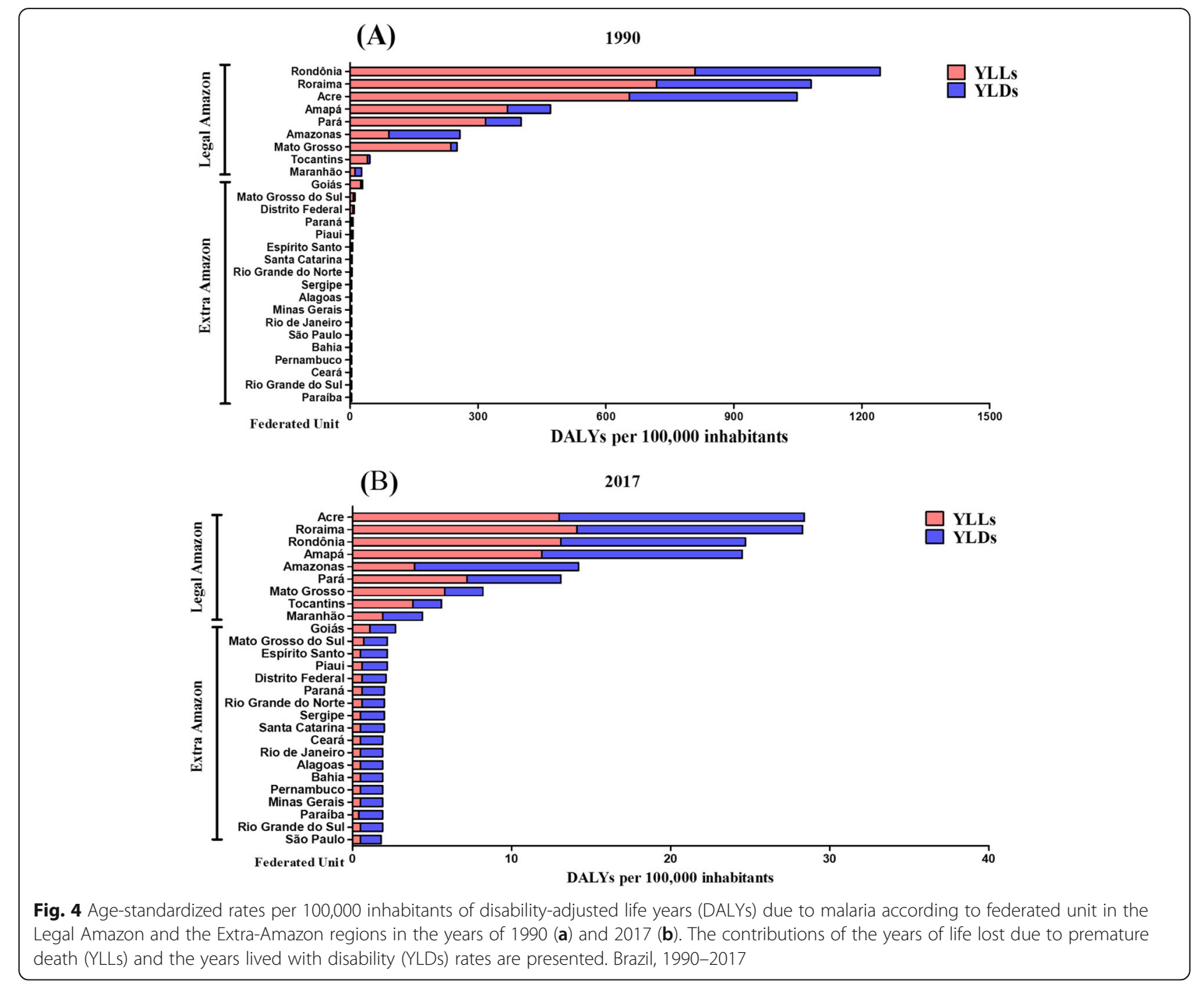

Altogether, the DALYs, YLLs, and YLDs gather information on mortality and morbidity and allow the estimation of the impact of each disease or injury on the health status of the population. Therefore, these indicators constitute remarkable tools for policy making aimed at reducing the burden of a disease [19-25].

The fact that Brazil is among the countries with the highest DALYs rates due to malaria in South America [40] highlights a situation that deserves attention. Despite the decrease in all the disease burden indicators between 1990 and 2017 (and particularly in the YLLs rate, which decreased by $95.4 \%$ in the period), we noted that the years of life lost due to disability (YLDs) currently constitute the most representative contribution to the DALYs estimates. This scenario may also be a reflex of the decrease in incidence and mortality rates due to the disease observed in the country over the years of study.

We observed that the DALYs, YLLs, and YLDs values over the years were comparable between genders.
However, in some geographic regions, men are at a higher occupational risk of contracting malaria as they frequently work in mines, fields, or forests at times of intense activity of the vectors-mosquitoes of the genus Anopheles that transmit the parasites to humans $[15,41,42]$.

Nevertheless, we observed differences when the age groups were analyzed according to gender. The reasons underlying the high rates of DALYs, YLLs, and YLDs observed among children in 1990 are still poorly understood. However, it should be noted that their immune systems are more susceptible to infections, which is likely one of the reasons why children are more affected than other age groups [43]. On the other hand, the higher DALYs rate observed in 2017 among males in the age group of " 20 to 24 years old" may be related to the occupational exposure or to the migration of individuals from this age group to high-risk areas [43, 44].

Noteworthy, the large contribution of the YLDs to the DALYs rate due to malaria in recent years in Brazil 


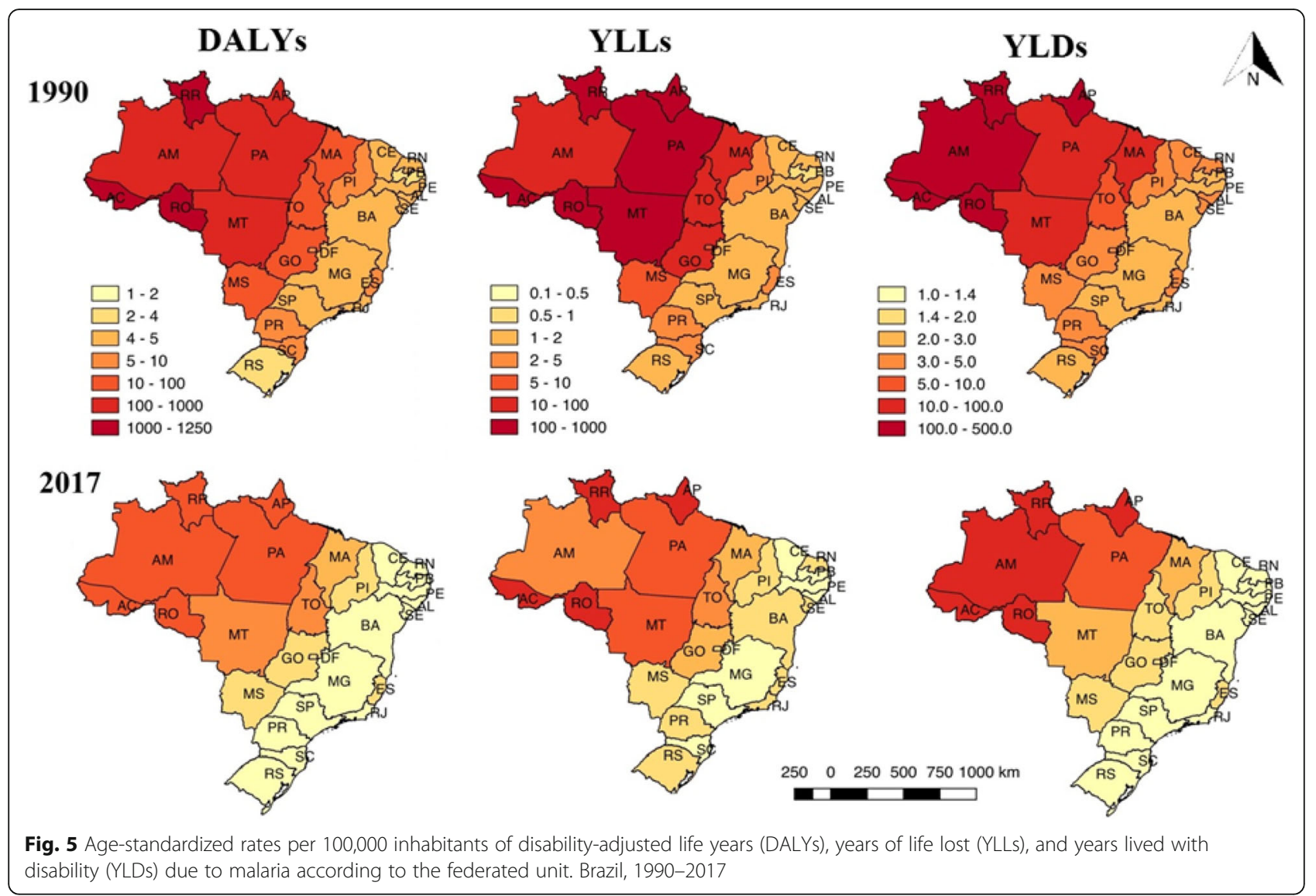

reflects the fact that this disease incapacitates those affected to carry out their routine activities (work and school, among others). Studies have shown that most cases of malaria in Brazil affect the economically productive age groups (individuals between 15 and 45 years old), thus indicating that the disease has an economic impact on the affected families due to the loss of productive hours of the patient. Therefore, greater investments are needed to control malaria, not only to reduce its impacts on individuals' health but also to minimize the economic pressure that it exerts on the population [45-47].

Among the Brazilian federated units, Acre, Rondônia, and Roraima, situated in the Amazon region (in the

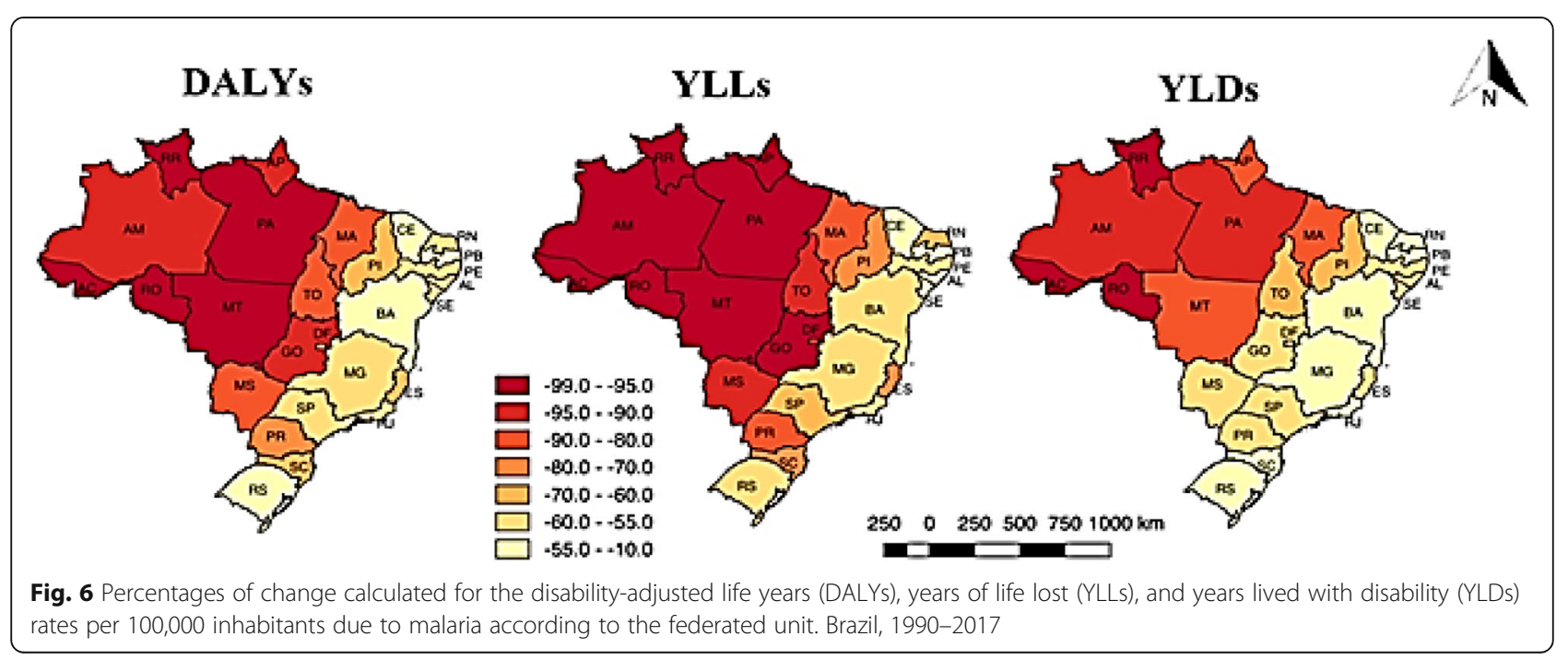




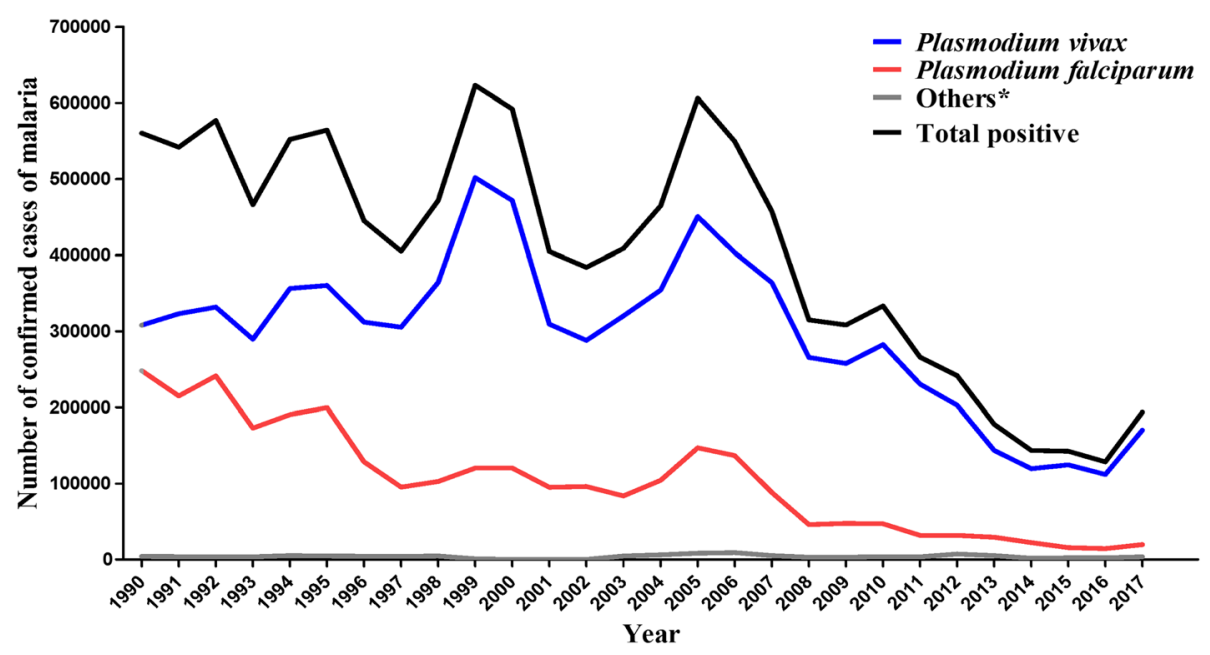

Fig. 7 Number of confirmed cases of malaria according to Plasmodium species. Brazil, 1990-2017. Sources: Brazilian Ministry of Health [37-39], National Health Foundation (Fundação Nacional de Saúde-FUNASA), and Epidemiological Surveillance Information System-Case Report (Sistema de Informação de Vigilância Epidemiológica - Notificação de casos_SIVEP/Malária). *Others = co-infections with P. vivax and P. falciparum, infections caused by P. malariae and P. ovale, and infections caused by non P. falciparum, according to the Brazilian Ministry of Health data classification

North of Brazil) had the highest incidence and DALYs rates in 1990 and 2017. The Brazilian Amazon, so-called Legal Amazon (Amazônia Legal) since 1953, is formed by the states of Acre, Amapá, Amazonas, Pará, Rondônia, Roraima, Tocantins, and part of the states of Maranhão and Mato Grosso). It presents environments that are favorable to malaria transmission, with risk factors that include poor demographic and socioeconomic conditions, and areas of expansion of the agricultural frontier, logging, road construction, and hydroelectric plants [11, 48-51].

The estimates of the GBD 2017 showed that in the 1990s the highest DALYs rates were observed in the states of Goiás (Central-West Brazil, in the ExtraAmazon region) and Mato Grosso (Central-West Brazil, within the Legal Amazon region). Both these regions received the highest proportion of cases from the North region of the country [16]. In non-endemic areas, the constant presence of infected individuals, along with the persistence of the vector, represents a continuous risk for the reintroduction of the natural transmission [50]. As observed in other states of the Legal Amazon region, Maranhão (which politically belongs to the Northeast region) has been undergoing a process of expansion of its agricultural frontiers since the 1970s and 1980s. This expansion is occurring particularly in the west and north frontiers of the state, in the pre-Amazonian region in the border with the state of Pará. These conditions helped exacerbate malaria transmission in 1986 and 1987 [52].

In the Extra-Amazon region, the state of Piauí (Northeast Brazil) presented the highest incidence rate of malaria in both 1990 and 2017. With the exception of Maranhão, which has part of its territory in the Legal Amazon, the sates in the Northeast of Brazil are considered non-endemic and generally report only sporadic imported cases of malaria. Piauí state records an average of 40 cases of malaria per year, half of which are probably autochthonous. These autochthonous cases are possibly from regions bordering the state of Maranhão [53].

Some authors have pointed out that the spread of malaria to areas outside the Amazon region in Brazil, and particularly to urbanized and industrialized states, is of major concern since these highly populated areas present favorable conditions for the spread of parasites and vectors $[13,54,55]$.

In American countries, P. vivax is the predominant parasite species and accounted for $74.1 \%$ of the cases of malaria in 2017. P. falciparum is generally considered the most important etiological agent of malaria in terms of mortality, while $P$. vivax is responsible for the majority of the infections, causing the disease in large areas of the world, including Brazil. An increasing number of reports has argued that the number of deaths due to infections by $P$. vivax is underestimated [7, 56, 57]. It is important to consider the parasite species when estimating disease burden because each species lead to different clinical manifestations of the disease $[43,58]$. In this sense, indicators of YLLs due to incapacity and premature death may greatly vary depending on the region evaluated and the predominant parasite species.

Three species of the genus Plasmodium were responsible for the 11,327,462 cases of malaria in Brazil between 1990 and 2017. P. vivax accounted for $73.5 \%$ of 
the reports, followed by $P$. falciparum (25.5\%). One percent of the cases were caused by other species. Noteworthy, $P$. vivax has been increasingly associated with severe malaria, leading to complications that include respiratory distress, shock, and anemia [59-62]. In Brazil, the cases of malaria are seldom caused by $P$. malariae, and those are usually restricted to specific Amazon regions and its surroundings [58, 63]. Therefore, the burden of the disease in the country is a result of the infections by $P$. vivax and $P$. falciparum. What should be emphasized is that each of these two species generates different burdens for malaria [58, 64, 65]. Additionally, factors such as the immunological and genetic characteristics of the exposed population, the climate and environmental conditions, the presence of vector control policies, and the use of antimalarial drugs can influence the burden of the disease $[43,58,65]$.

The main goals of the National Malaria Control Program (Programa Nacional de Controle da MaláriaPNCM) [66] of the Brazilian Ministry of Health are to reduce the case fatality rate and severity of cases, reduce the incidence of the disease, eliminate transmission in urban areas, and maintain the disease controlled in areas where the transmission has already been interrupted. The current scenario in the Amazon region is promising but still requires new approaches to eliminate transmission in the municipalities where it persists. The treatment for malaria adopted by the Brazilian Public Health System (Sistema Único de Saúde-SUS) is based on the use of active principles such as chloroquine and primaquine, among others [67].

Even though substantial progress has been made in reducing the burden of malaria in Brazil, planning actions for controlling the disease remains a priority, especially in the Legal Amazon. The risk of death due to malaria results from a combination of environmental, demographic, and others factors, which may result in highly localized risk patterns.

Although the GBD 2017 generated important estimates of the global burden of diseases, the study presents critical limitations regarding the coverage and quality of the Brazilian databases used. Another important limitation resides in the fact that their estimates do not consider the malaria burden caused by $P$. falciparum, $P$. vivax, and $P$. malariae separately. This may be taken into account in future studies, as the three parasite species cause different clinical manifestations, present distinct geographic distributions, and, therefore, should have their specific disease burden estimates $[58,68]$. P. vivax, for example, can cause multiple relapses, recrudescence, or reinfection following the elimination of infection from the blood due to its stage of hypnozoites in the liver $[64,65,69,70]$. Thus, it leads to a burden that is different from that caused by the other two parasite species.
Despite these limitations, based on the GBD 2017 estimates, our study showed a declining trend in malaria burden in Brazil during the 27-year study period. However, the disease persists as an important cause of loss of years of healthy life due to premature mortality and disability in the country. Understanding the geographic and temporal distribution of the risk of death and disability is essential for the planning, implementation, and refinement of control strategies aiming to eliminate the diseases.

\section{Conclusions}

The metrics estimated by the GBD 2017 allowed for a better understanding of the burden of malaria in the country and its federated units. Data showed that malaria has affected individuals of both sexes and in 2017 generated similar DALYs rates for different age groups. The highest DALYs rates are concentrated in the North region, likely due to the ecological, social, and migratory conditions that favor the occurrence and circulation of the parasites and the vectors. The persistence of malaria in the Amazon region urges for the constant evaluation of prevention and control measures. Despite the significant decrease in DALY of malaria in the country, it is necessary to maintain control and surveillance measures of the main transmission areas, focusing on the states and municipalities where the disease persists. Resource allocation for further research in the areas and populations most affected by the disease should also be encouraged. In addition, it is necessary to ensure adequate coverage, access, and quality of health services (diagnosis, treatment, and follow-up of cases) to the population in order to prevent the occurrence of severe forms of malaria.

\section{Abbreviations}

GBD: Global Burden of Diseases; YLLs: Years of life lost (due to premature death); YLDs: Years lived with disability; DALYs: Disability-adjusted life years; UI: Uncertainty intervals; WHO: World Health Organization; Cl: Confidence interval; IHME: Institute for Health Metrics and Evaluation; USA: United States of America; ICD: International Classification of Diseases; SIM: Sistema de Informações sobre Mortalidade; SINAN: Sistema de Informação de Agravos de Notificação; SIVEP: Sistema de Informação de Vigilância Epidemiológica; $\mathrm{SIH}$ : Sistema de Informações Hospitalares; SIA: Sistema de Informações Ambulatoriais; SUS: Sistema Único de Saúde; CODEm: Cause of Death Ensemble model; NTDs: Neglected tropical diseases; ARC: Annual rates of change; FUNASA: Fundação Nacional de Saúde; CAAE: Certificado de Apresentação para Apreciação Ética; PNCM: Programa Nacional de Controle da Malária; PNPD: Programa Nacional de Pós-Doutorado; Capes: Coordenação de Aperfeiçoamento de Pessoal de Nível Superior; CNPq: Conselho Nacional de Desenvolvimento Científico e Tecnológico; FAPERJ: Fundação Carlos Chagas de Amparo à Pesquisa do Estado do Rio de Janeiro; CNE: Cientistas do Nosso Estado; PPM: Programa Pesquisador Mineiro

\section{Acknowledgements}

JMTB is grateful to Programa Nacional de Pós-Doutorado-Coordenação de Aperfeiçoamento de Pessoal de Nivel Superior (PNPD/Capes) and the Programa de Pós-Graduação em Parasitologia/Universidade Federal de Minas Gerais for the postdoctoral fellowship awarded. GLW would like to thank Conselho Nacional de Desenvolvimento Científico e Tecnológico (CNPq/Brazil) for the 
research scholarship, and the Fundação Carlos Chagas de Amparo à Pesquisa do Estado do Rio de Janeiro (FAPERJ/Brazil) for the grant from the Programa Cientistas do Nosso Estado (CNE/2015). EMB is a level 1 research fellow from the Conselho Nacional de Desenvolvimento Científico e Tecnológico (CNPq/ Brazil). MC would like to thank the Conselho Nacional de Desenvolvimento Científico e Tecnológico (CNPq/Brazil) for the research fellowships, and the Fundação de Amparo à Pesquisa do Estado de Minas Gerais (FAPEMIG/Brazil) for the Programa Pesquisador Mineiro (PPM/2016).

\section{About this supplement}

This article has been published as part of Population Health Metrics, Volume 18 Supplement 1 2020: The GBD Brazil Network. The full contents of the supplement are available at https://pophealthmetrics.biomedcentral.com/ articles/supplements/volume-18-supplement-1.

\section{Authors' contributions}

JMTB, DSB, and MC participated in the study concept and design of the study. JMTB DSB, and MC performed the analysis of the data. JMTB, DSB, FRMM, GLW, EMB, PLT, and MC participated in interpretation of the data and critical revisions of the manuscript. The authors read and approved the final manuscript.

\section{Funding}

Publication costs, the GBD 2017 Brazilian database, and methods were funded by the Brazilian Ministry of Health through the agreement of the Secretariat of Health Surveillance and the Universidade Federal de Minas Gerais (Health Process no. 25000.479735/2017-40 TED 125/2017).

\section{Availability of data and materials}

The estimates of GBD 2017 are available on the GBD study platform at http://vizhub.healthdata.org/gbd-compare and http://ghdx.healthdata.org/ gbd-results-tool. The number of disease cases of malaria were obtained from (i) the SUS Epidemiological Report (Informe Epidemiológico do SUS) available at http://scielo.iec.gov.br/scielo.php?script=sci_arttext\&pid=S0104-16731 997000100004, from (ii) the National Health Foundation (Fundação Nacional de Saúde - FUNASA) available at http://www.funasa.gov.br/epi/malaria/ malaria0.htm, and from (iii) the Epidemiological Surveillance Information System - Case Report (Sistema de Informação de Vigilância Epidemiológica-Notificação de casos_SIVEP/Malária) available at http://2 00.214.130.44/sivep_malaria/

\section{Ethics approval and consent to participate}

The protocol for this study was approved by the Research Ethics Committee of the Federal University of Minas Gerais, Belo Horizonte, Brazil (Project CAAE 62803316.7.0000.5149)

\section{Consent for publication}

Not applicable

\section{Competing interests}

The authors declare that they have no competing interests.

\section{Author details}

${ }^{1}$ Laboratory of Epidemiology of Infectious and Parasitic Diseases, Department of Parasitology, Institute of Biological Sciences, Universidade Federal de Minas Gerais, Belo Horizonte, Avenida Presidente Antônio Carlos, 6627, Pampulha, Belo Horizonte, Minas Gerais 31270-901, Brazil. ${ }^{2}$ Federal Institute of Education, Science, and Technology of Ceará, Rua Francisco da Rocha Martins, S/N, Pabussu, Caucaia, Ceará 61609-090, Brazil. ${ }^{3}$ Department of Epidemiology, Social Medicine Institute, Universidade do Estado do Rio de Janeiro, Rua São Francisco Xavier 524, Maracanã, Rio de Janeiro 20550-013, Brazil. ${ }^{4}$ Institute for Public Health Studies, Universidade Federal do Rio de Janeiro, Avenida Horácio Macedo, S/N, Ilha do Fundão - Cidade Universitária, Rio de Janeiro 21941-598, Brazil. '5aboratory of Malaria, Department of Parasitology, Institute of Biological Sciences, Universidade Federal de Minas Gerais, Belo Horizonte, Avenida Presidente Antônio Carlos, 6627, Pampulha, Belo Horizonte, Minas Gerais 31270-901, Brazil. '5Chool of Medicine, Postgraduate Program in Tropical Medicine, Universidade de Brasília, Campus Universitário Darcy Ribeiro, Asa Norte, Brasília, Distrito Federal 70910-900, Brazil. ${ }^{7}$ Post-Graduation Program in Health Sciences, Infectology and Tropical
Medicine, Universidade Federal de Minas Gerais, Avenida Professor Alfredo Balena, 190, Santa Efigênia, Belo Horizonte, Minas Gerais 30130-100, Brazil.

Received: 18 May 2020 Accepted: 22 June 2020

Published: 30 September 2020

\section{References}

1. World Health Organization. World malaria report 2017; 2017. https:/www.who. int/malaria/publications/world-malaria-report-2017/en/. Accessed 12 Dec 2018.

2. Centers for Disease Control and Prevention. Parasites - Malaria; 2018. https:// www.cdc.gov/parasites/malaria/index.html: 2018 Accessed 14 Dec 2018.

3. White NJ. Plasmodium knowlesi: The Fifth Human Malaria Parasite. Clin Infect Dis. 2008:46:172-3.

4. Hellemond JJ, Rutten M, Koelewijn R, Zeeman AM, Verweij JJ, Wismans PJ, et al. Human Plasmodium knowlesi Infection Detected by Rapid Diagnostic Tests for Malaria. Emerg Infect Dis. 2009;15:1478-80.

5. Malta DC, Duarte EC, Almeida MF, Dias MAS, Morais Neto OL, Moura L. List of avoidable causes of deaths due to interventions of the Brazilian Health System. Epidemiol Serv Saúde. 2007;16:233-44 (in Portuguese).

6. Duarte EC, Ramalho WM, Tauil PL, Fontes CJF, Pang L. The changing distribution of malaria in the Brazilian Amazon, 2003-2004 and 2008-2009. Rev Soc Bras Med Trop. 2014;47(6):763-9.

7. Cowman AF, Healer J, Marapana D, Marsh K. Malaria: Biology and Disease. Cell. 2016;167:610-24.

8. World Health Organization. Malaria - Deaths; 2018a. https://www.who.int/ malaria/en/. Accessed 13 Dec 2018.

9. Pan American Health Organization. Situación de la Malaria en la Región de las Américas, 2000-2016; 2017. https://www.paho.org/hq/index.php?option= com_docman\&view=download\&category_slug=statistics-data-maps-81 09\&alias=45344-situation-malaria-region-americas-2000-2016-344\&ltemid= 270\&lang=pt. Accessed 12 Dec 2018

10. Pan American Health Organization. Epidemiological Update - Increase of malaria in the Americas; 2018. https://reliefweb.int/report/world/ epidemiological-update-increase-malaria-americas-30-january-2018. Accessed 15 Dec 2018.

11. Tauil P, Deane L, Sabroza P, Ribeiro C. A malária no Brasil. Cad Saúde Pública. 1985;1:71-111.

12. Deane LM. Malaria studies and control in Brazil. Am J Trop Med Hyg. 1988; 38:223-30.

13. Pina-Costa A, Brasil P, Santi SMD, Araujo MP, Suárez-Mutis MC, Santelli ACFS, et al. Malaria in Brazil: what happens outside the Amazonian endemic region. Mem Inst Oswaldo Cruz. 2014;109:618-33.

14. Silva R, Paiva CHA. The Juscelino Kubitschek government and the Brazilian Malaria Control and Eradication Working Group: collaboration and conflicts in Brazilian and international health agenda, 1958-1961. Hist Ciên Saúde Manguinhos. 2015;22:95-114.

15. Ferreira UM, Castro MC. Challenges for malaria elimination in Brazil. Malar J. 2016:15:1-18.

16. Marques AC, Pinheiro EA. Flows of malaria cases in Brazil in 1980. Rev Bras Malariol Doen Trop. 1982;34:1-31.

17. Chaves SS, Rodrigues LC. An initial examination of the epidemiology of malaria in the State of Roraima, in the Brazilian Amazon Basin. Rev Inst Med Trop. 2000;42:269-75.

18. Ministério da Saúde. Malária - Descrição da Doença; 2018. http://portalms. saude.gov.br/saude-de-a-z/malaria/descricao-da-doenca. Accessed 22 Jan 2019.

19. GBD 2016 Global, regional, and national under-5 mortality, adult mortality, age-specific mortality, and life expectancy, 1970-2016: a systematic analysis for the Global Burden of Disease Study 2016. Lancet. 2017a; 390:1084-1150.

20. GBD 2016 Global, regional, and national age-sex specific mortality for 264 causes of death, 1980-2016: a systematic analysis for the Global Burden of Disease Study 2016. Lancet. 2017b; 390:1151-1210.

21. GBD 2016 Global, regional, and national incidence, prevalence, and years lived with disability for 328 diseases and injuries for 195 countries, 19902016: a systematic analysis for the Global Burden of Disease Study 2016. Lancet. 2017C; 390:1211-1259.

22. GBD 2016 Global, regional, and national disability-adjusted life-years (DALYs) for 333 diseases and injuries and healthy life expectancy (HALE) for 195 countries and territories, 1990-2016: a systematic analysis for the Global Burden of Disease Study 2016. Lancet. 2017d; 390:1260-1344.

23. GBD 2016 Global, regional, and national comparative risk assessment of 84 behavioural. environmental and occupational, and metabolic risks or 
clusters of risks, 1990-2016: a systematic analysis for the Global Burden of Disease Study 2016. Lancet. 2017e; 390:1345-1422.

24. Institute for Health Metrics and Evaluation. Global Burden of Disease: history; 2018a. http://www.healthdata.org/gbd/about/history. Accessed 14 Dec 2018

25. Institute for Health Metrics and Evaluation. The Global Burden of Disease: a critical resource for informed policymaking; 2018b. http://www.healthdata. org/gbd/about. Accessed 14 Dec 2018.

26. Instituto Brasileiro de Geografia e Estatística. Projeção da população do Brasil e das Unidades da Federação; 2018. https://www.ibge.gov.br/apps/ populacao/projecao/. Accessed 13 Dec 2018.

27. Instituto Brasileiro de Geografia e Estatística. Divisões Regionais do Brasil; 2017. https://www.ibge.gov.br/geociencias-novoportal/cartas-e-mapas/redesgeograficas/15778-divisoes-regionais-do-brasil.html. Accessed 14 Dec 2018.

28. Ministério da Saúde. Malária - Situação Epidemiológica - Dados Região Amazônica e Extra-Amazônica; 2019a. http://portalms.saude.gov.br/saudede-a-z/malaria/situacao-epidemiologica-dados. Accessed 20 Feb 2019.

29. Institute for Health Metrics and Evaluation. ICD codes; 2018c. http://www. healthdata.org/sites/default/files/files/data_for_download/2012/IHME_GBD2 010_CauseListandICD.pdf. Accessed 13 Dec 2018.

30. Marinho F, Passos VMA, França EB. New century, new challenges: changes in the burden of disease profile in Brazil, 1990-2010. Epidemiol Serv Saúde. 2016;25:713-24 (in Portuguese).

31. França EB, Passos VMA, Malta DC, Duncan BB, Ribeiro ALP, Guimarães MDC, et al. Cause-specific mortality for 249 causes in Brazil and states during 1990-2015: a systematic analysis for the global burden of disease study 2015. Popul Health Metrics. 2017;15:1-17.

32. Souza MFM, França EB, Cavalcante A. Burden of disease and health situation analysis: results of the Global Burden of Disease (GBD) Brazil network. Rev Bras Epidemiol. 2017;20:1-3.

33. Martins-Melo FR, Carneiro M, Ramos AR Jr, Heukelbach J, Ribeiro ALP, Werneck GL. The burden of Neglected Tropical Diseases in Brazil, 1990-2016: A subnational analysis from the Global Burden of Disease Study 2016. PLoS Neglec Trop Dis. 2018;12:e0006559.

34. Bezerra JMT, Araújo VEM, Barbosa DS, Martins-Melo FR, Werneck GL, Carneiro M. Burden of leishmaniasis in Brazil and federated units, 1990-2016: Findings from Global Burden of Disease Study 2016. PLoS Neglec Trop Dis. 2018;12:e006697.

35. Institute for Health Metrics and Evaluation. GBD Compare: life expectancy; 2018d. https://vizhub.healthdata.org/gbd-compare/. Accessed 14 Dec 2018.

36. Global Burden of Diseases. GBD Compare - Data visualizations (Annual Rate of Change); 2017f. https://vizhub.healthdata.org/gbd-compare/\#. Accessed 01 Feb 2019.

37. Ministério da Saúde. Série histórica de casos de agravos e doenças infecciosas e parasitárias Brasil, 1980 a 1996 - Malária; 1997. http://scielo.iec.gov.br/scielo. php?script=sci_arttext\&pid=S0104-16731997000100004. Accessed 22 Jan 2019.

38. Ministério da Saúde. Fundação Nacional de Saúde (FUNASA). Plano de Intensificação das Ações de Controle da Malária na Amazônia Legal: documento técnico; 2002. http://www.funasa.gov.br/epi/malaria/malaria0, htm. Accessed 22 Jan 2019.

39. Ministério da Saúde. Sistema de Informação de Vigilância EpidemiológicaNotificação de casos - SIVEP/Malária; 2019b. http://200.214.130.44/sivep_ malaria/. Accessed 10 Mar 2019.

40. Global Burden of Diseases. GBD Compare - Data visualizations; 2017g. https://vizhub.healthdata.org/gbd-compare/. Accessed 22 Jan 2019.

41. Reuben R. Women and Malaria - Special Risks and Appropriate Control Strategy. Soc Sci Med. 1993;37:473-80.

42. Vlassoff C, Manderson L. Incorporating gender in the anthropology of infectious disease. Trop Med Int Health. 1998;3:1011-9.

43. Guinovart C, Navia MM, Tanner M, Alonso PL. Malaria: Burden of Disease. Curr Mol Med. 2006;6:137-40.

44. Renault CS, Bastos FA, Filgueira JPPS, Filgueira JPPS, Homma TK. Malaria's epidemiology situacion in the city of Belém - Pará. Rev Par Med. 2007;21: 19-24 (in Portuguese).

45. Ajani OIY, Ashagidigbi WM. Effect of Malaria on Rural Households' Farm Income in Oyo State, Nigeria. Afr J Biomed Res. 2008;11:259-66.

46. Purdy M, Robinson M, Wei K, Rublin D. The Economic Case for Combating Malaria. Am J Trop Med Hyg. 2013;89:819-23.

47. Gunda R, Chimbari MJ, Mukaratirwa S. Assessment of Burden of Malaria in Gwanda District, Zimbabwe, Using the Disability Adjusted Life Years. Int J Environ Res Public Health. 2016;13:1-12.
48. Oliveira-Ferreira J, Lacerda VGM, Brasil P, Ladislau JLB, Tauil PL, Daniel-Ribeiro CT. Malaria in Brazil: an overview. Malar J. 2010;9:1-15.

49. Braz RM, Guimarães RF, Carvalho Júnior OA, Tauil PL. Spatial dependence of malaria epidemics in municipalities of the Brazilian Amazon. Rev Bras Epidemiol. 2014;17:615-28.

50. Barata RB. Malaria in Brazil: trends in the last ten years. Cad Saúde Pública. 1995;11:128-36 (in Portuguese)

51. Cesário M, Cesário RR. Malaria, the Amazon and development. Sci Am Brasil. 2006;54:54-5 (in Portuguese).

52. Silva AR, Fernandes JMC, Rodrigues TA, Santos HJ, Cavalheiro NNM, Guimarães MC, et al. Controle da malária no Estado do Maranhão. Rev Soc Bras Med Trop. 2009;42:318-24.

53. Nascimento JAA, Guimarães LM, Carvalho-Costa FA. Malaria epidemiology in the State of Piauí, Northeastern Brazil: a retrospective study with secondary data. Rev Soc Bras Med Trop. 2016;49:99-103.

54. Lorenz C, Virginio F, Aguiar BS, Suesdek L, Chiaravalloti-Neto F. Spatial and temporal epidemiology of malaria in extra-Amazonian regions of Brazil. Malar J. 2015;14:1-13.

55. Costa AP, Bressan CS, Pedro RS, Valls-de-Souza R, Silva S, Souza PR, et al. Delayed diagnosis of malaria in a dengue endemic area in the Brazilian extra-Amazon: recent experience of a malaria surveillance unit in State of Rio de Janeiro. Rev Soc Bras Med Trop. 2010b;43:571-4 (in Portuguese).

56. Naing C, Whittaker MA, Nyunt Wai V, Mak JW. Is Plasmodium vivax malaria a severe malaria?: a systematic review and meta-analysis. PLoS Neglec Trop Dis. 2014;8:e3071.

57. Siqueira AM, Mesones-Lapouble O, Marchesini P, Sampaio VS, Brasil P, Tauil $\mathrm{PL}$, et al. Plasmodium vivax Landscape in Brazil: Scenario and Challenges. Am J Trop Med Hyg. 2016;95:87-96.

58. Byass P, de Courten M, Graham WJ, Laflamme L, McCaw-Binns A, Sankoh OA, et al. Reflections on the Global Burden of Disease 2010 Estimates. PLoS Med. 2013;10:e1001477.

59. Alexandre MA, Ferreira CO, Siqueira AM, Magalhães BL, Mourão MPG, Lacerda MV, et al. Severe Plasmodium vivax Malaria. Brazilian Amazon Emerg Infect Dis. 2010;16:1611-4.

60. Lança EFC, Magalhães BML, Vitor-Silva S, Siqueira AM, Benzecry SG, Alexandre MAA, et al. Risk Factors and Characterization of Plasmodium Vivax-Associated Admissions to Pediatric Intensive Care Units in the Brazilian Amazon. PLoS One. 2012;7:e35406.

61. Raposo CCBS, Santos JB, Santos GMC, Gonçalves EGR, Silva AR. Plasmodium vivax malaria: related factors to severity in the State of Maranhão, Brazil. Rev Soc Bras Med Trop. 2013;46:67-72.

62. Gonçalves LA, Cravo P, Ferreira MU. Emerging Plasmodium vivax resistance to chloroquine in South America: an overview. Mem Inst Oswaldo Cruz 2014;109:534-9.

63. Scopel KKG, Fontes CJF, Nunes AC, Horta MF, Braga EM. High prevalence of Plamodium malariae infections in a Brazilian Amazon endemic area (Apiacás-Mato Grosso State) as detected by polymerase chain reaction. Acta Trop. 2004;90:61-4.

64. Imwong M, Snounou G, Pukrittayakamee S, Tanomsing N, Kim JR, Nandy A, et al. Relapses of Plasmodium vivax infection usually result from activation of heterologous hypnozoites. J Infect Dis. 2007;195:927-33.

65. Badirzadeh B, Naderimagham S, Asadgol Z, Mokhayeri Y, Khosravi A, Tohidnejad E, et al. Burden of Malaria in Iran, 1990-2010: findings from Global Burden of Disease Study 2010. Arch Iran Med. 2016;19:241-7.

66. Ministério da Saúde. Programa Nacional de Prevenção e Controle da Malária - PNCM; 2003. http://bvsms.saude.gov.br/bvs/publicacoes/programa_nac_ prev_malaria.pdf. Accessed 19 Mar 2019.

67. Ministério da Saúde. Sistema de Vigilância em Saúde. Guia prático de tratamento da malária no Brasil; 2010. http://bvsms.saude.gov.br/bvs/ publicacoes/guia_pratico_malaria.pdf. Accessed 24 Jan 2019.

68. Coura JR, Suárez-Mutis M, Ladeia-Andrade S. A new challenge for malaria control in Brazil: asymptomatic Plasmodium infection - A Review. Mem Inst Oswaldo Cruz. 2006;101:229-37.

69. Bousema T, Drakeley C. Epidemiology and infectivity of Plasmodium falciparum and Plasmodium vivax gametocytes in relation to malaria control and elimination. Clin Microbiol Rev. 2011;24:377-410.

70. Val FF, Sampaio VS, Cassera MB, Andrade RT, Tauil PL, Monteiro WM, et al. Plasmodium vivax malaria elimination: should innovative ideas from the past be revisited? Mem Inst Oswaldo Cruz. 2014;109:522-4.

\section{Publisher's Note}

Springer Nature remains neutral with regard to jurisdictional claims in published maps and institutional affiliations. 